\title{
Food avoidance in irritable bowel syndrome leads to a nutrition-deficient diet
}

\author{
Stevenson C, ${ }^{1}$ Master of Science, Postgraduate Student; Blaauw $\mathbf{R},{ }^{1} \mathrm{PhD}$, Associate Professor and Acting Head

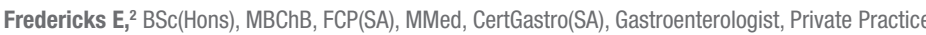 \\ Visser $\mathbf{J},{ }^{1}$ Master of Nutrition; Postgraduate Programme Coordinator and Senior Lecturer; Roux $\mathbf{S},{ }^{2}$ DMedScience, Associate Professor \\ 'Division of Human Nutrition, Faculty of Medicine and Health Sciences, Stellenbosch University \\ 2Department of Biochemistry and Microbiology, Nelson Mandela Metropolitan University, Port Elizabeth \\ Correspondence to: Cheryl Stevenson, e-mail: cheryl@retaildc.co.za \\ Keywords: irritable bowel syndrome, dietary intake, fibre, fructose
}

\section{Abstract}

Objective: The objective was to assess the dietary intake of subjects with irritable bowel syndrome (IBS) and to compare it to that of international recommendations. The hypothesising assumption of this study was that a situation in which subjects insist that diet or trigger foods play a part in symptom generation may lead to an unbalanced dietary intake.

Design: This was a descriptive observational study, with an analytical component

Setting: A private, secondary care-level clinic in South Africa.

Subjects: The study population comprised 122 participants. Each subject completed an estimated, three-day dietary record. The data were analysed using a computerised food analysis programme. The fructose intake was analysed semi-quantitatively. IBS subjects' protein and carbohydrate intake were significantly higher than the recommended dietary allowance for protein and carbohydrate $(p$-values $<0.000$ and $<0.000$, respectively).

Outcome measures: The identification of dietary risk factors that affect IBS.

Results: The IBS subjects' daily total dietary fibre $(15.13 \mathrm{~g} \pm 13.11)$ was significantly lower $(p$-value $<0.000)$ than the dietary reference intake (DRI) target intake of $24.76 \mathrm{~g} /$ day, and the intake of micronutrients, (calcium, iron and folate) was significantly less than the DRI. There was no significant difference in macronutrient intake between the diarrhoea-predominant IBS (D-IBS), constipation-predominant IBS (C-IBS) and the control groups. The total number of fructose serves per day was not statistically significant between the three groups (C-IBS 2.68 \pm 1.68, D-IBS $2.15 \pm 1.86$, and controls $3.17 \pm 2.39$, $p$-value $=0.157$ ).

Conclusion: The IBS subjects in this study consumed diets that were deficient in key micronutrients and total fibre when judged against the recommended DRIs. Dietary adjustments may have been tailored by subjects to minimise symptom development and this led to nutritionally deficient diets.

(P) Peer reviewed. (Submitted: 2013-03-26. Accepted: 2013-08-09.) ๑ SAJCN

S Afr J Clin Nutr 2014;27(1):25-30

\section{Introduction}

Irritable bowel syndrome (IBS) is a chronic disorder that is characterised by abdominal pain or discomfort, and associated with disordered defecation, either C-IBS, D-IBS, or mixed or alternating symptoms of constipation and diarrhoea. ${ }^{1}$ It is estimated that IBS affects $3-25 \%$ of the general population. Patients with IBS can account for up to $30-50 \%$ of gastroenterology clinic visits. ${ }^{2}$ Treatment and management of the condition is often unsatisfactory, and there is no single curative treatment. Despite numerous reviews on IBS and diet, it is very difficult to give general dietary advice to patients with IBS. This is partly because of the complexity of the condition, heterogeneity of the patient population and poor understanding of the aetiology of the disorder. Dietary experts may play a very positive role in managing such patients. However, more definitive guidelines that outline a constructive approach for the dietitian are needed to treat patients with IBS. Definitive guidelines would support the unique skills of dietitians with regard to habitual eating and therapeutic dietary manipulation assessment. There is a dire need for further prospective research on dietary factors and IBS. Published data suggest that IBS symptoms may be caused or exacerbated by one or more dietary components in at least $25 \%$ of patients. ${ }^{3}$ Many patients restrict their dietary intake or eliminate certain provocative dietary agents in order to reduce the symptoms. The restriction of certain trigger foods could potentially distort macro- and micronutrient intake and place IBS individuals at risk of low nutrient intake.

Recent work has identified a collection of short-chain carbohydrates that are poorly absorbed in the small intestine, namely fermentable oligo-, di-, and monosaccharides and polyols (FODMAPs). ${ }^{4.5}$ These 
include fructo-oligosaccharides, galacto-oligosaccharides and polyols. ${ }^{6}$ Failure to completely absorb fructose in the small intestine leads to its delivery into the colonic lumen, together with water, because of its osmotic effect. If sufficient fructose reaches the colon, luminal distention may occur because of the osmotic load, as well as rapid gas production. Potentially, this leads to bloating, abdominal discomfort and motility changes. These symptoms are commonly experienced by patients with IBS. Malabsorption of dietary fructose may trigger symptoms in patients with IBS and the removal of fructose from the diet may improve them.

Dietary fibre, classified as soluble or insoluble, is a collective term for different plant substances that are resistant to digestion by human gastrointestinal enzymes. In the USA and the European Union, adult dietary fibre intake falls well below the recommended range of $20-35 \mathrm{~g} /$ day. $^{8}$ Currently, fibre supplementation is recommended to patients with IBS and constipation because greater insoluble fibre intake results in softer and bulkier stools, thus promoting colonic peristalsis and easing defecation. ${ }^{9}$ Many patients with IBS selfprescribe fibre supplements before consulting a physician because of the belief that alimentary habits play a significant role in their symptom development. ${ }^{10,11}$

Actual dietary behaviour in patients with IBS may differ from that of healthy controls, and has not been extensively reported. To date, only a few studies have assessed the dietary intake of patients with IBS. ${ }^{12-14}$ It is important that the latter is fully understood before any dietary recommendations or interventions are given. The aim of this study was to propectively assess the dietary intake of patients with IBS and to compare this with the international recommendations for healthy dietary intake, namely the dietary reference intakes (DRIs), ${ }^{15-}$ ${ }^{18}$ and secondly, to compare the intake of patients with IBS to that of healthy controls. The hypothesising assumption was that a situation in which subjects insist that diet or trigger foods play a part in symptom generation may lead to an unbalanced diet.

\section{Method}

\section{Study subjects}

This study was a descriptive observational study, with an analytical component, that identified dietary risk factors that affect IBS. The study population was men and women recruited at a private, secondary care-level clinic in South Africa. Data were collected between July 2008 and June 2012. Subjects were screened by a gastroenterologist and recruited according to the study inclusion criteria and their willingness to participate.

Exclusion criteria for both controls and cases included:

- Being unable to give informed consent.

- Being younger than 18 years of age.

- Being unable to understand English or Afrikaans.

- Having had a chronic infectious disease, e.g. human immunodeficiency virus (HIV) or tuberculosis.

- Being unable to tolerate a colonoscopy procedure.

- Pregnant or breastfeeding mothers.

- Having had any previous abdominal surgery, besides an appendectomy, a Caesarean, tubal laproscopic cholecystectomy, abdominal wall hernia repair or a hysterectomy.

- Currently taking antibiotics or gastrointestinal motility medication.

- Having a history of organic intestinal disease.
In order to establish whether or not there was a difference in dietary intake among the studied IBS population, subjects were divided into subtypes: C-IBS and D-IBS. However, patients with alternating or mixed-type IBS were excluded for the purposes of the study. A diagnosis of IBS was made using Rome II criteria. Controls included any patients who visited the clinic for routine screening procedures, for example, cancer screening and to exclude IBS. They were also included based on their willingness to participate in the study. Cases and controls were neither age, nor sex matched.

Written informed consent to participate was obtained from each participant on enrolment. The study was approved by the Research Ethics Committee at Nelson Mandela Metropolitan University (Reference No HUM07.70.2), and was conducted according to the ethical guidelines and principles of the International Declaration of Helsinki.

\section{Medical information}

Collected pertinent medical information included recent antibiotic usage, current medication, background medical history, previous bowel surgery, a family history of IBS, being a smoker or nonsmoker, IBS duration, IBS symptom triggers and anti-IBS-specific medication.

\section{Dietary assessment}

A registered dietitian explained and orientated each study subject on the required procedure to complete a prospective, estimated threeday dietary record. Portion sizes were determined using household food measures; for example, spoons, cups, bowls and a ruler. The results were analysed using FoodFinder ${ }^{\mathrm{TM}}$ III, a computerised nutritional analysis programme for South African foods. ${ }^{15}$ To examine the energy and nutrient content of the subjects' diets, the intakes were compared to the DRI values for adults aged 31-50 years and 51-70 years. ${ }^{16-19}$ Micronutrient (calcium, iron, vitamin C, folate and vitamin A) intake was compared to the relevant DRIs. The percentage energy intake for protein, fat and carbohydrates was compared to that outlined in the UK National Diet and Nutrition Survey. ${ }^{20,21}$ The subjects' diets were also analysed semi-quantitatively, using tables of known FODMAP content by a dietitian for fructose intake, based on their three-day food record. This method has been described elsewhere. ${ }^{4,7}$

\section{Statistical analyses}

Summary statistics were used to describe the variables. Mean values were used as the measures of central location for continuous responses, and standard deviations (SDs) as indicators of spread. The relationship between continuous response variables and nominal input variables was analysed using appropriate analysis of variance (ANOVA); for example, for homogenous variance among the groups. One-way ANOVA was utilised to assess variance. When heterogeneity of variances was detected with the Brown-Forsythe test, the data were analysed as per the Welch-Satterthwaite ANOVA. If the residuals were not normally distributed, a nonparametric ANOVA method, e.g. the Kruskal-Wallis test, was used. Multiple comparisons were assessed as per the Bonferroni test, provided that the ANOVA $p$-value was significant $(p<0.05)$. A $p$-value of less than 0.05 represented statistical significance. Statistica ${ }^{\circledR}$ version 9 was employed for all data analysis, and Statistical Analysis Software ${ }^{\circledR}$ version 9.1 for the Brown-Forsythe tests. 
Table I: The demographics of the 122 subjects

\begin{tabular}{|c|c|c|c|c|c|}
\hline & $\begin{array}{c}\text { All subjects } \\
(n=122)\end{array}$ & $\begin{array}{l}\text { Controls } \\
(n=19)\end{array}$ & $\begin{array}{c}\text { C-IBS } \\
(n=69)\end{array}$ & $\begin{array}{c}\text { D-IBS } \\
(n=34)\end{array}$ & p-value \\
\hline $\begin{array}{l}\text { Age in years } \\
\text { (mean } \pm S D \text { ) }\end{array}$ & $48.29 \pm 13.56$ & $56.9 \pm 13.66$ & $47.2 \pm 12.45$ & $45.7 \pm 14.14$ & 0.008 \\
\hline $\begin{array}{l}\text { BMl in } \mathrm{kg} / \mathrm{m}^{2} \\
(\text { mean } \pm \mathrm{SD})\end{array}$ & $27.82 \pm 6.88$ & $26.80 \pm 7.48$ & $28.07 \pm 6.81$ & $27.89 \pm 6.81$ & 0.779 \\
\hline Gender (male/female) & $20 / 102$ & $9 / 10$ & $4 / 65$ & $7 / 27$ & 0.000 \\
\hline
\end{tabular}

BMI: body mass index, C-IBS: constipation-predominant irritable bowel syndrome, D-IBS: diarrhoea-predominant irritable bowel syndrome, SD: standard deviation

\section{Results}

\section{Subjects' demographics}

The subjects' demographics are shown in Table I. In total, 122 subjects participated in the study and completed the three-day food record. There was a significant difference in age between the subjects in the three groups at baseline. Fifty-seven per cent ( $\mathrm{n}=69)$ of the subjects were diagnosed with C-IBS and $28 \%$ $(\mathrm{n}=34)$ with D-IBS, while $16 \%(\mathrm{n}=19)$ were controls (non-IBS). The majority $(75 \%)$ of IBS subjects were female $(n=92)$. Nine per cent of the IBS subjects were male $(n=11)$. As expected, the majority of the subjects were women. There was an almost equal number of males

Table II: The daily energy and nutrient intake of the irritable bowel syndrome group (combined constipation-predominant irritable bowel syndrome (C-IBS) and diarrhoeapredominant irritable bowel syndrome (D-IBS) (mean \pm standard deviation) compared with dietary reference intake (recommended daily allowance or adequate intake where available)

\begin{tabular}{|l|c|c|c|}
\hline Total daily intakes & $\begin{array}{c}\text { IBS participants } \\
(\mathbf{n}=103)\end{array}$ & RDA/AI & p-value \\
\hline Energy intake $(\mathrm{MJ})$ & $8.63 \pm 4.7$ & $8.9^{\mathrm{a}}$ & 0.560 \\
\hline Carbohydrates $(\mathrm{g})$ & $216.37 \pm 101.86$ & $130^{\mathrm{b}}$ & $<0.000$ \\
\hline Protein $(\mathrm{g})$ & $88.01 \pm 119.04$ & $47.1^{\mathrm{c}}$ & $<0.000$ \\
\hline Fat $(\mathrm{g})$ & & - & - \\
\hline \% energy from carbohydrates & $44.68 \pm 9.54$ & $47^{\mathrm{d}}$ & 0.015 \\
\hline \% energy from protein & $15.7 \pm 6.51$ & $15^{\mathrm{d}}$ & 0.281 \\
\hline \% energy from fat & $36.54 \pm 7.77$ & $33^{\mathrm{d}}$ & $<0.000$ \\
\hline Total dietary fibre $(\mathrm{g})$ & $15.13 \pm 13.11$ & $24.76^{\mathrm{e}}$ & $<0.000$ \\
\hline Calcium $(\mathrm{mg})$ & $619.33 \pm 308.04$ & $1077.67^{\mathrm{f}}$ & $<0.000$ \\
\hline Iron $(\mathrm{mg})$ & $11.26 \pm 9.38$ & $13.24^{\mathrm{g}}$ & 0.035 \\
\hline Vitamin C $(\mathrm{mg})$ & $93.3 \pm 89.68$ & $76.6^{\mathrm{h}}$ & 0.061 \\
\hline Folate $(\mu \mathrm{\mu g})$ & $186.23 \pm 103.01$ & $400^{\mathrm{i}}$ & $<0.000$ \\
\hline Vitamin A $(\mu \mathrm{g})$ & $712.86 \pm 600.45$ & $721.36^{\mathrm{j}}$ & 0.886 \\
\hline A & & & \\
\hline
\end{tabular}

Al: adequate intake, IBS: irritable bowel syndrome, RDA: recommended daily allowance a: Estimated average requirement for energy intake, weighted for the study population ${ }^{18}$ b: Recommended dietary intake for carbohydrates ${ }^{18}$

c: Recommended dietary intake for protein, weighted for the study population. The recommended daily allowance for protein for men and women aged $31-70$ years is $56 \mathrm{~g} /$ day and $46 \mathrm{~g} /$ day, respectively ${ }^{18}$

$\mathrm{d}$ : Population average, based on the UK survey ${ }^{22}$

e: Adequate intake for total dietary fibre, weighted for the study population. Adequate intake of total fibre for men aged 31-50 years and 51-70 years is $38 \mathrm{~g} /$ day and $30 \mathrm{~g} /$ day, respectively. Adequate intake of total fibre for women aged $31-50$ years and $51-70$ years, is $25 \mathrm{~g} /$ day and $21 \mathrm{~g} /$ day, respectively ${ }^{18}$

$\mathrm{f}:$ Adequate intake for calcium, weighted for the study population. Adequate intake of calcium for men and women aged $31-50$ years is $1000 \mathrm{mg} /$ day, and for men and women aged $51-70$ years, $1200 \mathrm{mg} / \mathrm{day} \mathrm{y}^{19}$

$\mathrm{g:} \mathrm{Recommended} \mathrm{daily} \mathrm{allowance} \mathrm{for} \mathrm{iron,} \mathrm{weighted} \mathrm{for} \mathrm{the} \mathrm{study} \mathrm{population.} \mathrm{The} \mathrm{recommended} \mathrm{daily} \mathrm{allowance} \mathrm{of} \mathrm{iron}$ for men aged 31-70 years is $8 \mathrm{mg} /$ day. The recommended daily allowance of iron for women aged $31-50$ years and $51-70$ years is $18 \mathrm{mg} /$ day and $8 \mathrm{mg} /$ day, respectively ${ }^{19}$

h: Recommended daily allowance for vitamin C, weighted for the study population. The recommended daily allowance for men aged $31-70$ years is $90 \mathrm{mg} /$ day and for women aged $31-70$ years, $75 \mathrm{mg} / \mathrm{day}^{20}$

i: Recommended daily allowance for folate ${ }^{19}$

j: Recommended daily allowance for vitamin A, weighted for the study population. The recommended daily allowance for men aged 31-70 years is $900 \mu \mathrm{g} / \mathrm{day}$, and for women aged 31-70 years, $700 \mu \mathrm{g} / \mathrm{day}^{19}$
(9) and females (10) in the control group. The mean body mass index (BMI) of the three groups fell within the overweight range.

\section{The dietary intake of subjects with irritable bowel syndrome compared with that in the dietary recommendations}

The mean $( \pm S D)$ daily intakes for energy, macronutrients and selected micronutrients for the subjects are presented in Table II, and were compared to DRls, recommended dietary allowances (RDAs) and adequate intakes, where available. Protein and carbohydrate intake was significantly higher than the RDAs for protein and carbohydrates ( $p$-values $<0.000$ and $<0.000$, respectively). When this was expressed as the percentage energy intake from the diet, carbohydrate intake significantly differed to that of the population-based average in the UK study. However, protein intake did not. ${ }^{20,21}$ There is no DRI for absolute intake of fat. However, the percentage of energy from fat was significantly higher than that of the populationbased average in the UK study. ${ }^{20,21}$ Daily total dietary fibre $(15.13 \mathrm{~g} \pm 13.11)$ was significantly lower ( $p$-value $<0.000$ ) than the DRI target intake of $24.76 \mathrm{~g} /$ day. The intake of micronutrients (calcium, iron and folate) was significantly less than the DRI (Table II). The subgroups, C-IBS and D-IBS, were also compared separately to the RDA. No significant differences were found when the two groups were combined, except for iron intake. The dietary intake for the constipation-predominant IBS group was not significantly different to RDA, but it was significantly different for the diarrhoea-predominant IBS group (9.925 $\mu \mathrm{g} \pm 5.786)(p$-value $=0.002)$.

\section{The dietary intake of participants according to the different groups (constipation-predominant irritable bowel syndrome and diarrhoea-predominant irritable bowel syndrome and controls)}

The data were analysed to establish whether or not there was any difference between the IBS subtypes and the control group. The mean $( \pm S D$ ) daily intake of energy, macronutrients and selected micronutrients are summarised in Table III. Total energy intake and macronutrient distribution did not differ significantly between the groups. The constipation-predominant IBS group had the highest intake of fat at $86.6 \pm 62.78$ /day.

There was no significant difference in dietary intake between the three groups

Figure 1 shows that total dietary fibre intake did not reach the recommended intake for all three groups, but was 
Table III: The daily energy and nutrient intake of the study population (mean \pm standard deviation), constipation-predominant irritable bowel syndrome, diarrhoea-predominant irritable bowel syndrome and controls

\begin{tabular}{|c|c|c|c|c|}
\hline Intake & D-IBS (n = 34) & C-IBS $(n=69)$ & Controls $(n=19)$ & p-value \\
\hline Energy kJ (kcal) & $\begin{array}{c}8036.44 \pm 3552.91 \\
(1913 \pm 846)\end{array}$ & $\begin{array}{c}8928.9 \pm 5166.18 \\
(2126 \pm 1230)\end{array}$ & $\begin{array}{c}7808.65 \pm 2128.66 \\
(1859 \pm 507)\end{array}$ & 0.476 \\
\hline Carbohydrates (g) & $205.57 \pm 89.61$ & $221.7 \pm 107.60$ & $219.07 \pm 58.16$ & 0.710 \\
\hline Protein $(\mathrm{g})$ & $70.23 \pm 38.15$ & $96.77 \pm 142.53$ & $75.21 \pm 26.43$ & 0.466 \\
\hline Fat $(g)$ & $78.92 \pm 42.39$ & $86.8 \pm 62.78$ & $68.97 \pm 27.52$ & 0.411 \\
\hline Carbohydrates (\% energy) & $44.16 \pm 8.49$ & $44.93 \pm 10.07$ & $49.17 \pm 8.82$ & 0.157 \\
\hline Protein (\% energy) & $14.81 \pm 3.42$ & $16.13 \pm 7.57$ & $16.32 \pm 3.17$ & 0.541 \\
\hline Fat (\% energy) & $36.98 \pm 8.37$ & $36.31 \pm 7.51$ & $32.91 \pm 7.78$ & 0.167 \\
\hline Saturated fatty acids & $25.75 \pm 12.31$ & $29.32 \pm 26.97$ & $22.31 \pm 10.38$ & 0.417 \\
\hline Polyunsaturated fatty acids & $18.61 \pm 10.51$ & $20.77 \pm 11.98$ & $15.06 \pm 8.23$ & 0.132 \\
\hline Monounsaturated fatty acids & $26.90 \pm 16.5$ & $28.47 \pm 25.11$ & $24.19 \pm 10.93$ & 0.733 \\
\hline Cholesterol (mg) & $246.03 \pm 139.5$ & $333.36 \pm 407.73$ & $250.01 \pm 132.18$ & 0.345 \\
\hline Total dietary fibre $(\mathrm{g})$ & $15.14 \pm 9.22$ & $15.13 \pm 14.72$ & $17.50 \pm 6.04$ & 0.746 \\
\hline Insoluble dietary fibre (g) & $4.36 \pm 2.91$ & $3.66 \pm 2.17$ & $5.16 \pm 3.16$ & 0.064 \\
\hline Soluble dietary fibre $(\mathrm{g})$ & $3.96 \pm 3.51$ & $2.83 \pm 1.66$ & $3.93 \pm 2.26$ & 0.055 \\
\hline Calcium (mg) & $572.60 \pm 358.34$ & $642.35 \pm 279.98$ & $662.68 \pm 269.45$ & 0.464 \\
\hline Iron (mg) & $9.92 \pm 5.79$ & $11.92 \pm 10.70$ & $11.47 \pm 5.06$ & 0.561 \\
\hline Vitamin C (mg) & $81.76 \pm 71.45$ & $98.97 \pm 97.4$ & $123.47 \pm 108.54$ & 0.293 \\
\hline Folate $(\mu \mathrm{g})$ & $177.46 \pm 76.13$ & $190.54 \pm 114.22$ & $189.32 \pm 54.14$ & 0.808 \\
\hline Vitamin A $(\mu \mathrm{g})$ & $582.04 \pm 419.65$ & $777.32 \pm 665.26$ & $899.11 \pm 694.20$ & 0.154 \\
\hline
\end{tabular}

C-IBS: constipation-predominant irritable bowel syndrome, D-IBS: diarrhoea-predominant irritable bowel syndrome

higher in the control group than it was in the IBS groups. The IBS groups had a poorer intake of fibre compared to that in the controls. Although it was not statistically significant, there was a trend for the constipation-predominant IBS group to have the poorest intake of soluble fibre, when compared to both the D-IBS and control groups $(p$-value $=0.055)$.

\section{Fructose intake}

Fructose intake was assessed in $n=115$ subjects [consti-pationpredominant IBS $(n=64)$, D-IBS $(n=33)$ and controls $(n=18)]$. The total number of fructose serves per day was not statistically significant among the three groups [constipation-predominant IBS $(2.68 \pm 1.68)$, D-IBS $(2.15 \pm 1.86)$ and controls $(3.17 \pm 2.39)$, $\mathrm{p}$-value $=0.157]$. The diarrhoea-predominant IBS participants had the lowest intake of fructose (in excess of glucose) per day. The high fructose intake in all three groups was mostly attributed to the intake of high corn starch-containing soda or fizzy drinks (the fructose to glucose ratio is 55:45), and secondly to fruits with a high fructose content.

\section{Discussion}

The purpose of this observational study was to assess the dietary intake of subjects with IBS and to establish whether or not any alteration in dietary intake impacted on nutrient intake, or whether or not any dietary intake could explain the presentation of IBS symptoms.

The results of this study revealed nutritional inadequacies in the IBS population. The subjects in this study reported on the consumption of a diet with a macronutrient composition that met recommended intakes, with the exception of total dietary fibre intake, which fell

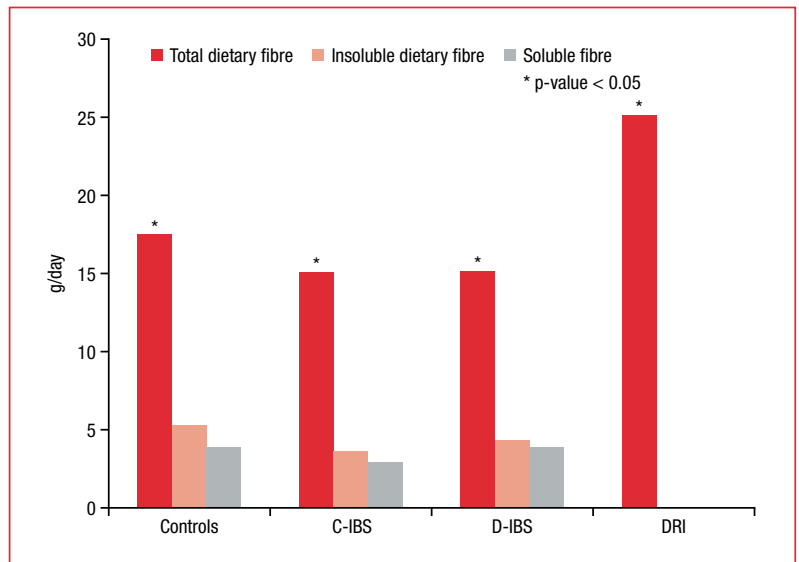

C-IBS: constipation-predominant irritable bowel syndrome, D-IBS: diarrhoea-predominant irritable bowel syndrome, DRI: dietary reference intake

*:p-value $<0.05$ was significantly different to dietary reference intake

Figure 1: The dietary fibre intake of constipation-predominant irritable bowel syndrome, diarrhoea-predominant irritable bowel syndrome and the controls, compared to the dietary reference intake

significantly below the recommendation. The latter finding is similar to that of Park et al..$^{8}$ In that study, it was observed that American and European diets contain inadequate fibre. A further study by Park et al also highlighted poor fibre intake in a group of women with IBS. ${ }^{22}$ A randomised, multicentre, open clinical trial ${ }^{23}$ compared the effect of a partially hydrolysed guar gum (PHGG) supplement (soluble fibre) with that of a wheat bran supplement (insoluble fibre) on a large number of patients with C-IBS and D-IBS. Significant improvements in bowel movement normalisation and abdominal pain relief were found in patients receiving the $5 \mathrm{~g} /$ day PHGG, compared to those receiving the $30 \mathrm{~g} /$ day of wheat bran. In a recent systematic review 
and meta-analysis of 12 studies that compared fibre with placebo or no treatment in 591 patients, ispaghula husk (soluble fibre) and not wheat bran, was shown to be an effective treatment for IBS ${ }^{24}$ The latter finding highlights the beneficial effects of increasing soluble fibre, particularly PHGG, in patients with C-IBS and D-IBS.

Short-chain fatty acids (SCFAs) are linked to a decreased likelihood of IBS..$^{24,25}$ The rate and amount of SCFA production depends on the species and number of microflora present in the colon, the substrate source and gut transit time..$^{26}$ The poor fibre intake seen in the participants with IBS in this study would influence SCFA production. SCFAs aid in the relaxation of resistance vessels in the colonic vasculature, help support blood flow to the liver and colon, ${ }^{27}$ and enhance colonic muscular contraction, thereby contributing to laxation and relief from constipation. ${ }^{28}$

Therefore, SCFAs may alleviate certain IBS symptoms, particularly if altered central nervous system sensory processing and disturbed autonomic nervous system regulation are aetiological factors for IBS. ${ }^{29}$ In a study by Tana et al, patients with IBS showed significantly higher levels of acetic, propionic, and total organic, acid, than that in controls. ${ }^{30}$ Higher organic acid levels were also associated with more severe symptoms and impaired quality of life.

Recent published data strongly suggest that dysbiosis in the microbiota of patients with IBS patients plays an important role in the presentation of IBS. The faecal microbiota of patients with IBS differs significantly to those of healthy subjects. ${ }^{31}$ Tana et al showed that patients with IBS had significantly higher counts of Veillonella and Lactobacillus, but did not differentiate these findings between IBS subtypes..$^{30}$ Codling et al found that there was significantly more variation in the gut microbiota of healthy volunteers than in those of patients with IBS, and concluded that the gut microbiota within the colon are influenced by the disease in IBS. ${ }^{32}$ Owing to the positive role that fibre plays in SCFA production and gut microbiota symbiosis, the recommendation to increase soluble fibre intake, in particular, in this group of patients with IBS may be beneficial.

The C-IBS group had the highest BMI, although it was not significantly different from that of the diarrhoea-predominant IBS and control groups. A potential relationship exists between overweight/obesity and constipation. A few studies have reported on an association between obesity and constipation. ${ }^{33,34}$

Inflammation may play a role in functional gastrointestinal disorders. It has been hypothesised that obesity may increase the risk of functional gastrointestinal disorders, owing to the release of proinflammatory cytokines. Secondly, the association could be attributed to excess abdominal fat exerting extra pressure on the colon, leading to slower mobility and possible metabolism. Or alternately, the longer that fermentable food remains in the colon, the longer the gut microbiota can ferment it and release extra energy, contributing to obesity. The higher fat content of the C-IBS subjects diets could have aggravated the development of symptoms in this subset of subjects. Dietary advice to decrease dietary fat content may be valuable. ${ }^{35}$

To date, there has been no evidence that patients with functional bowel symptoms consume more FODMAPs than those without symptoms. ${ }^{36}$ In this study, it was found that subjects with IBS consumed a very comparable amount of fructose to that of healthy controls. The number of fructose serves per day eaten by IBS subjects was similar to that found by Croagh et al. ${ }^{37}$ Fructose is a common part of the Western diet. FODMAPs are not the cause of functional bowel disorders, but may be a useful tool in the dietary treatment and management of IBS. ${ }^{38}$ The efficacy of a dietitian-delivered, lowFODMAP diet has been demonstrated in published studies. Reducing the dietary intake of FODMAPS has been shown to lead to a marked improvement in bowel symptoms. ${ }^{7,39,40}$ In view of the latter findings, it is probable that the IBS subjects in this study would benefit from dietary counselling aimed at a reduction in fructose intake, particularly as the majority of fructose consumed by the subjects was from high-fructose corn syrup in sweetened cold drinks.

The IBS subjects in this study had a poor micronutrient intake of calcium, folate and iron. However, the symptoms for a poor calcium, folate and iron intake are not synonymous with IBS symptoms. Hence, it would appear that subjects altered or restricted their diets in order to manage their IBS symptoms, which may have adversely affected their nutrient intake.

The D-IBS group showed an insufficient intake of vitamin A. This is similar to the findings of Aller et al. ${ }^{41}$ Vitamin $A$ and its derivatives have been shown to regulate the growth and differentiation of gastrointestinal epithelial cells. Amit-Romach et al showed that a vitamin A-deficient diet compromised the function of the gastrointestinal mucosal epithelial barrier. ${ }^{42}$ This may be one of the underlying mechanisms in the aetiology of diarrhoea-predominant IBS.

There are inherent limitations in utilising an estimated three-day food record to assess nutritional intake. This prospective method of dietary assessment may be influenced by the presence of active IBS symptoms, which could have distorted usual dietary intake. Hence, it is important to concurrently assess symptom severity. Further research to assess the validity and reliability of the three-day food record or diary in patients with IBS would be useful.

Lastly, supplementation usage was recorded, but not reported, because less than $10 \%$ of subjects used supplements (varying brands).

\section{Conclusion}

The findings of this study suggest that IBS may have an impact on the dietary intake of patients with IBS. Therefore, patients with IBS should be assessed for inadequate intake of key nutrients, specifically fibre. Dietary advice should be given and supplements recommended, where appropriate. Patients with IBS may be at risk of low micronutrient intake.

All three groups demonstrated a poor fibre intake, which is a growing concern in the Westernised diet. ${ }^{43}$ There were more similarities than differences in the IBS groups and controls with regard to the consumption of foods that have frequently been implicated to worsen IBS symptoms. The lack of differences in dietary intake may be the result of an absence of awareness or education that certain food may worsen symptoms, namely, fructose. This prospective study evaluated and compared the dietary content in C-IBS and D-IBS subjects, and found the diets to be deficient in micronutrients and fibre. The IBS subjects may have adjusted their diets to alleviate symptom development, and this may have resulted in nutritionally deficient diets. 
Patients with C-IBS were found to have a higher fat intake, while those with D-IBS had an insufficient vitamin A intake, both of which could have contributed to their IBS symptoms. It is recommended that patients with C-IBS and D-IBS are managed differently as their clinical presentation may vary in pathogenesis. Further research on the cause-effect relationship between dietary composition and the resultant SCFAs or gut microbiota is needed. The role that the organic acids and gut microbiota composition play in the aetiology of IBS symptoms has yet to be strongly demonstrated. There is a dire need for research that demonstrates a strong relationship between dietary composition, microbiota and SCFAs found in patients with either C-IBS or D-IBS. The role that diet plays with regard to microbiota and their by-products, and to what extent this may contribute to the pathogenesis of C-IBS and D-IBS, also requires further exploration.

\section{Declaration}

Mrs Stevenson's work was funded by the National Research Foundation, South Africa (Gun number 2075266).

\section{Conflict of interest}

Prof Roux, Prof Blaauw, Dr Fredericks and Mrs Visser declare no potential conflict of interest.

\section{References}

1. Longstreth GF, Thompson WG, Chey WD, et al. Functional bowel disorders Gastroenterology. 2006;130(5):1480-1491.

2. McFarland LV, Dublin S. Meta-analysis of probiotics for the treatment of irritable bowel syndrome. World J Gastroenterol. 2008:14(17):2650-2661.

3. Floch MH. Use of diet and probiotic therapy in the irritable bowel syndrome. J Clin Gastroenterol. 2005;39 (5 Suppl 3):S243-S246.

4. Gibson PR, Newham E, Barrett JS, et al. Review article: fructose malabsorption and the bigger picture. Aliment Pharmacol Ther. 2007;25(4):349-363.

5. Gibson PR, Shepherd SJ. Evidence-based dietary management of functional gastrointestinal symptoms: the FODMAP approach. J Gastroenterol Hepatol. 2010;25(2):252-258

6. Barrett JS, Gearry RB, Muir JG, et al. Dietary poorly absorbed, short-chain carbohydrates increase delivery of water and fermentable substrates to the proximal colon. Aliment Pharmacol Ther. 2010;31(8):874-882.

7. Shepherd SJ, Gibson PR. Fructose malabsorption and symptoms of irritable bowel syndrome: guidelines for effective dietary management. J Am Diet Assoc. 2006;106(10):1631-1639

8. Park Y, Hunter DJ, Spiegelman D, et al. Dietary fiber intake and risk of colorectal cancer: a pooled analysis of prospective cohort studies. JAMA. 2005;294(22):2849-2857.

9. Giannini EG, Mansi C, Dulbecco P, et al. Role of partially hydrolysed guar gum in the treatment of irritable bowel syndrome. Nutrition. 2006;22(3):334-342.

10. Bennett WG, Cerda JJ. Benefits of dietary fiber, myth or medicine? Postgrad Med 1996;99(2):153-175

11. Paterson WG, Thompson WG, Vanner SJ, et al. Recommendations for the management of irritable bowel syndrome in general practice. Can Med Assoc J. 1999;161(2):154-160.

12. Hyo Jung $P$, Jarrett $M$, Heitkemper M. Quality of life and sugar and fiber intake in women with irritable bowel syndrome. West J Nurs Res. 2010;32(2):218-232.

13. Williams $E A$, Nai $X$, Corfe BM. Dietary intakes in people with irritable bowel syndrome. BMC Gastroenterol. 2011;11:9

14. Ligaarden SC, Farup PG. Low intake of vitamin $B_{6}$ is associated with irritable bowel syndrome symptoms. Nutr Res. 2011;31(5):356-361.

15. FoodFinder version 3. Dietary analysis software program. Parow Valley: Nutritional Intervention Research Unit, South African Medical Research Council; 2000.

16. Dietary reference intakes for energy, carbohydrate, fiber, fat, fatty acids, cholesterol, protein and amino acids. 2002/2005. The National Academies Press [homepage on the Internet]. c2009. Available from: http://iom.edu/Activities/Nutrition/SummaryDRIs/ / media/Files/Activity\%20Files/Nutrition/DRIs/ULs\%20for\%20Vitamins\%20and\%20 Elements.pdf

17. Dietary reference intakes for vitamin $A$, vitamin $K$, arsenic, boron, chromium, copper, iodine, iron, manganese, molybdenum, nickel, silicon, vanadium and zinc. The National Academies Press [homepage on the Internet]. 2001. c2009. Available from: http://iom. edu/Activities/Nutrition/SummaryDRIs/ /media/Files/Activity\%20Files/Nutrition/DRIs/ ULs\%20for\%20Vitamins\%20and\%20Elements.pdf
18. Dietary reference intakes for vitamin $C$, vitamin $E$, selenium and carotenoids. The National Academies Press [homepage on the Internet]. 2000. c2009. Available from: http://iom.edu/Activities/Nutrition/SummaryDRIs/ /media/Files/Activity\%20Files/ Nutrition/DRIs/ULs\%20for\%20Vitamins\%20and\%20Elements.pdf

19. Dietary reference intakes for thiamin, riboflavin, niacin, vitamin $B_{6}$, folate, vitamin $B_{12}$, pantothenic acid, biotin and choline. The National Academies Press [homepage on the Internet]. 1998. c2009. Available from: http://iom.edu/Activities/Nutrition/ SummaryDRIs/ /media/Files/Activity\%20Files/Nutrition/DRIs/ULs\%20for\%20 Vitamins\%20and\%20Elements.pdf

20. Henderson L, Irving K, Gregory J, et al. The national diet and nutrition survey: adults aged 16-64 years. Volume 2: Energy, protein, carbohydrate, fat and alcohol intake. London: TS0; 2003.

21. Henderson L, Irving K, Gregory J, et al. The national diet and nutrition survey: adults aged 19-64 years. Volume 3: Vitamin and mineral intake and urinary analytes. London: TSO; 2003.

22. Park HJ, Jarrett M, Heitkemper M. Quality of life and sugar and fiber intake in women with irritable bowel syndrome. West J Nurs Res. 2010;32(2):218-232.

23. Parisi GC, Zilli M, Miani MP, et al. High fiber diet supplementation in patients with irritable bowel syndrome (IBS). Dig Dis Sci. 2002;47(8)8:1697-1704.

24. Ford AC, Talley NJ, Spiegel BMR, et al. Effect of fibre, antispasmodics, and peppermin oil in the treatment of irritable bowel syndrome: systematic review and meta-analysis BMJ. 2008;337:a2313.

25. Cavaglieri CR, Nishiyama A, Fernandes LC, et al. Differential effects of short-chain fatty acids on proliferation and production of pro- and anti-inflammatory cytokines by cultured lymphocytes. Life Sci. 2003;73(13):1683-1690.

26. Tedelind S, Westberg F, Kjerrulf M, et al. Anti-inflammatory properties of the shortchain fatty acids acetate and propionate: a study with relevance to inflammatory bowel disease. World J Gastroenterol. 2007;28(13):2826-2832

27. Wong JMW, de Souza R. Colonic health: fermentation and short chain fatty acids. J Clin Gastroenterol. 2006;40(3):235-243

28. Mortensen FV, Nielsen $\mathrm{H}$. In vivo and in vitro effects of short chain fatty acids on intestina blood circulation. In: Cummings JH, Rombeau JL, Sakata T, editors. Physiological and clinical aspects of short chain fatty acids. Cambridge: Cambridge University Press, 1995; p. 391-400.

29. Yajima T. Contractile effects of short chain fatty acids on the isolated colon of the rat. $J$ Physiol. 1985;368:667-678.

30. Tana C, Umesaki Y, Imaoka A, et al. Altered profiles of intestinal microbiota and organic acids may be the origin of symptoms in irritable bowel syndrome. Neurogastroenterol Motil. 2010;22(5):512-519, e114-e115.

31. Kassinen A, Krogius-Kurikka L, Mäkivuokko H, et al. The fecal microbiota of irritable bowel syndrome patients differs significantly from that of healthy subjects. Gastroenterology. 2007:133(1):24-33.

32. Codling C, O'Mahony L, Shanahan F, et al. A molecular analysis of fecal and mucosa bacterial communities in irritable bowel syndrome. Dig Dis Sci. 2010;55(2):392-397.

33. Pourhoseingholi MH, Kaboli SA, Pourhoseingholi $A$, et al. Obesity and functional constipation; a community-based study in Iran. J Gastrointestin Liver Dis. 2009;18(2):151-155.

34. Pecora P, Suraci C, Antonelli M, et al. Constipation and obesity: a statistical analysis. Boll Soc It Biol Sper. 1981;57(23):2384-2388.

35. Rangnekar AS, Chey WD. The FODMAP diet for irritable bowel syndrome: food fad or roadmap to a new treatment paradigm? Gastroenterology. 2009;137(1):383-386.

36. Barrett JS, Irving PM, Shepherd SJ, et al. Comparison of the prevalence of fructose and lactose malabsoprtion across chronic intestinal disorders. Aliment Pharmacol Ther. 2009:30(2):165-174

37. Croagh C, Shepherd SJ, Berryman M, et al. Pilot study on the effect of reducing dietary FODMAP intake on bowel function in patients without a colon. Inflamm Bowel Dis. 2007;13(12):1522-1528.

38. Gibson PR. Food intolerance in functional bowel disorders. J Gastroenterol and Hepatol. 2011;26 Suppl 3:128-131.

39. Goldstein R, Braverman D, Stankiewicz. Carbohydrate malabsorption and the effect of dietary restriction on symptoms of irritable bowel syndrome and functional bowel complaints. Isr Med Assoc J. 2000;2(8):583-587

40. Shepherd SJ, Parker FC, Muir JZG, et al. Dietary triggers of abdominal symptoms in patients with irritable bowel syndrome: randomized placebo-controlled evidence. Clin Gastroenterol Hepatol. 2008:6(7):765-771.

41. Aller R, de Luis DA, Izaola 0 , et al. Dietary intake of a group of patients with irritable bowel syndrome: relation between dietary fiber and symptoms. An Med Interna. 2004;21(12):577-580

42. Saito YA, Locke GR, Weaver AL, et al. Diet and functional gastrointestinal disorders: a population-based case-contol study. Am J Gastroenterol. 2005;100(12):2743-2748. 